\title{
Hyperkalaemic periodic paralysis: a rare presentation of Addison's disease
}

\author{
J.M. Sowden and D.Q. Borsey \\ Glan Clwyd Hospital, Bodelwyddan, Nr Rhyl, Clwyd LL18 5UJ Wales, UK.
}

\begin{abstract}
Summary: A 44 year old man with longstanding diabetes mellitus gave a 6-month history of periodic attacks of flaccid quadriplegia. Following one of these episodes he was admitted for assessment. In view of persistent hyperkalaemia, hypoadrenalism was suspected and Addison's disease was confirmed biochemically. Adrenal replacement therapy restored the potassium levels to normal and resulted in no further attacks of paralysis.
\end{abstract}

\section{Introduction}

Hyperkalaemic periodic paralysis (HPP) is a rare and potentially fatal complication of hypoadrenalism. We report a patient who had periodic hyperkalaemic flaccid quadriplegia as the presenting manifestation of Addison's disease.

\section{Case report}

A 44 year old man with a 21-year history of insulin dependent diabetes was hospitalized as an emergency. For 6 months he had experienced occasional episodes of profound limb weakness and paraesthesia during which he was unable to rise from a chair. These attacks were of insidious onset, tended to occur whilst resting after exertion, and lasted 3 to 4 hours. They were not associated with hypoglycaemia and between episodes he was asymptomatic. During the week preceding admission they had occurred daily and admission was precipitated by a paralytic episode accompanied by vomiting and drowsiness. For 4 weeks he had suffered from recurrent sore throats associated with general malaise. He denied postural dizziness or weight loss. Recent glycaemic control had been satisfactory.

On admission he was pale, sweating, apyrexial, tachypnoeic and dehydrated with a ketotic foetor. There was no abnormal pigmentation. The pulse was regular at 100 beats per minute and the blood pressure $70 / 40 \mathrm{mmHg}$ supine. He was hypotonic with markedly reduced limb power and diminished deep tendon reflexes. Plantar reflexes were flexor. There was no sensory loss. Fundoscopy revealed background diabetic retinopathy.

Initial investigations showed a serum sodium of

Correspondence: D.Q. Borsey, M.R.C.P.

Accepted: 1 November 1988
$127 \mathrm{mmol} / 1$, potassium $7.6 \mathrm{mmol} / \mathrm{l}$, urea $10.7 \mathrm{mmol} / \mathrm{l}$, chloride $101 \mathrm{mmol} / 1$, blood glucose $25.3 \mathrm{mmol} / \mathrm{l}$. The arterial $\mathrm{pH}$ was $7.18, \mathrm{PCO}_{2} 3.1 \mathrm{kPa}, \mathrm{PO}_{2} 15.2 \mathrm{kPa}$ and actual bicarbonate $8.0 \mathrm{mmol} / 1$. The calculated anion gap was expanded at $25.6 \mathrm{mmol} / \mathrm{l}$ and this, combined with marked ketonuria and glycosuria, suggested diabetic ketoacidosis. The electrocardiogram showed changes consistent with hyperkalaemia with tall and peaked T-waves.

He was treated with an infusion of fluids and soluble insulin. $5 \mathrm{mmol} / \mathrm{l}$ of calcium chloride was administered intravenously for its cardioprotective effect. Within one hour his weakness had resolved and his blood pressure was $110 / 70 \mathrm{mmHg}$. At 8 hours serum sodium was $127 \mathrm{mmol} / \mathrm{l}$, potassium $7.3 \mathrm{mmol} / \mathrm{l}$, bicarbonate $16 \mathrm{mmol} / \mathrm{l}$ and blood glucose $12.1 \mathrm{mmol} / \mathrm{l}$. Following $200 \mathrm{mmol} / 1$ of $8.4 \%$ sodium bicarbonate intravenously, serum potassium fell to $5.0 \mathrm{mmol} / \mathrm{l}$ and bicarbonate rose to $23 \mathrm{mmol} / \mathrm{l}$. Within 48 hours of admission he was completely well and had returned to his previous subcutaneous insulin regime.

However, recurrence of hyperkalaemia $(6.7 \mathrm{mmol} / \mathrm{l})$ suggested adrenal insufficiency. Short and prolonged tetracosactrin (Synacthen) tests were performed (Table I) and both showed low basal cortisol levels with no significant increase following Synacthen. In addition, high titres of adrenal antibodies were demonstrated in serum. It was felt that these results were sufficient to diagnose Addison's disease and so ACTH levels were not measured. He was treated with hydrocortisone $30 \mathrm{mg} /$ day and fludrocortisone $0.1 \mathrm{mg} /$ day and has since been normokalaemic and asymptomatic.

\section{Discussion}

The periodic paralyses are classified as primary or secondary and also as hypokalaemic, normokalaemic

The Fellowship of Postgraduate Medicine, 1989 
Table I Results of short and prolonged Synacthen tests

\begin{tabular}{|c|c|c|}
\hline \multirow[b]{2}{*}{$\begin{array}{l}\text { Time after } \\
\text { Synacthen }(250 \mu \mathrm{g})\end{array}$} & \multicolumn{2}{|c|}{$\begin{array}{l}\text { Serum cortisol } \\
(\text { nmol } / l)\end{array}$} \\
\hline & $\begin{array}{c}\text { Short } \\
\text { Synacthen }\end{array}$ & $\begin{array}{l}\text { Prolonged } \\
\text { Synacthen }\end{array}$ \\
\hline $\begin{array}{l}\text { Baseline } \\
30 \mathrm{~min} \\
60 \mathrm{~min}\end{array}$ & $\begin{array}{l}239 \\
239 \\
275\end{array}$ & $\begin{array}{l}275 \\
288 \\
280\end{array}$ \\
\hline
\end{tabular}

Short Synacthen - cortisol levels measured after $250 \mu \mathrm{g}$ Synacthen i.m; Prolonged Synacthen - $1 \mathrm{mg}$ depot Synacthen i.m. for 3 days. Cortisol levels measured after $250 \mu \mathrm{g}$ Synacthen i.m. on fourth day.

or hyperkalaemic. The primary forms have an autosomal dominant inheritance and episodes of paralysis are associated with abnormal flux of potassium ions through muscle cell membranes. ${ }^{1}$ In the secondary forms cellular handling of potassium is normal but changes in extra-cellular potassium levels interfere with the generation of the muscle cell action potential. Secondary HPP, which is more frequently associated with renal disease $e^{2,3}$ than with adrenal insufficiency, is suggested by high serum potassium levels during an attack, persistent hyperkalaemia between episodes of paralysis (in contrast to primary forms) and by other manifestations of the underlying disorder. A characteristic vacuolar myopathy may be seen on muscle biopsy although this is more often a feature of the chronic primary periodic paralyses.

There have been 15 reported cases of HPP associated with adrenal insuffiency. ${ }^{4-18}$ Some of the earlier cases are poorly documented, with no record of how the diagnosis of Addison's disease was established. ${ }^{4,6,7}$ The age of the patients ranged from 18-68 years with 12 males and 3 females. Three patients also suffered with insulin-dependent diabetes mellitus. ${ }^{11,15,16}$

Typically, weakness may last from less than one hour to several days, be generalized or localized and is often ascending in type. Cranial and respiratory muscles are generally spared. There is frequently associated limb paraesthesia but usually no objective sensory loss. The paralysis often commences during the rest period after exercise although, paradoxically, mild exercise may abort an attack. Alcohol, cold exposure and a high potassium intake may also precipitate attacks. ${ }^{16}$ The hyperkalaemia results in depolarization of the muscle cell membrane which decreases neuromuscular excitability and leads to paralysis. However, there is no consistent correlation between the serum potassium level and the severity of the weakness. ${ }^{17}$ The cardiac effects of hyperkalaemia and the occasional involvement of respiratory muscles may be life threatening.

Although in this case the hyperkalaemia on admission was attributed to a combination of diabetic ketoacidosis and Addison's disease, another explanation could be hyporeninaemic hypoaldosteronism with or without type IV renal tubular acidosis. ${ }^{19}$ This condition is usually associated with diabetes and chronic renal impairment. Patients are often asymptomatic, but muscle weakness or cardiac arrhythmias may occur. There is reduced production of renin and partial resistance to aldosterone at the distal tubule. Adrenal gland function and cortisol production are unaffected. The failure of potassium/hydrogen ion exchange leads to acidosis, hyperkalaemia, hyperchloraemia and increased urinary bicarbonate loss. In order to overcome the tubular resistance to mineralocorticoids relatively high doses of fludrocortisone (up to $1.0 \mathrm{mg}$ daily) may be necessary. Although investigations to exclude hyporeninaemic hypoaldosteronism in this patient were not performed, the satisfactory response to treatment with hydrocortisone $30 \mathrm{mg}$ and fludrocortisone $0.1 \mathrm{mg}$ daily, combined with the normal chloride levels and abnormal adrenal stimulation tests, would make this diagnosis unlikely.

This patient is unusual because paralysis was the initial and sole symptomatic manifestation of Addison's disease. In five of the previously reported cases, paralysis developed in patients with established hypoadrenalism as a consequence of inadequate steroid replacement ${ }^{11,13,15}$ or the inappropriate administration of potassium supplements. ${ }^{6,12}$ The remaining patients generally had other symptoms and signs to suggest adrenal insufficiency. This case demonstrates that hyperkalaemic periodic paralysis may occur as a rare, potentially serious and yet entirely reversible complication of adrenal insufficiency.

\section{References}

1. Engel, A.G. Metabolic and endocrine myopathies. In: Walton, J. (ed.) Disorders of Voluntary Muscle. Churchill-Livingstone, Edinburgh, 1981, pp. 664-711.

2. Marchand, J.F. \& Finch, C.A. Fatal spontaneous potassium intoxication in patients with uremia. Arch Int Med 1944, 73: $384-390$.

3. Finch, C.A., Sawyer, C.G. \& Flynn, J.M. Clinical syndrome of potassium intoxication. Am J Med 1946, 1: $337-352$.

4. Nicholson, W.M. \& Spaeth, W. Some clinical manifestations of abnormal potassium metabolism. Southern Med $J$ 1949, 42: 77-83. 
5. Marks, L. \& Feit, E. Flaccid quadriplegia, hyperkalemia and Addison's disease. Arch Intern Med 1953, 91: 56-67.

6. Bull, G.M., Carter, A.B. \& Lowe, K.G. Hyperpotassaemic paralysis. Lancet 1953, ii: 60-63.

7. Richardson, G.O. \& Sibley, J.C. Flaccid quadriplegia associated with hyperpotassaemia. Can Med Assoc J 1953, 69: 504-506.

8. Laporte, A., Goulon, M., Mercier, J-N. \& Leborgne, P. Paralysies récidivantes avec hyperkaliemie, secondaires a l'ingestion répétée de CIK, chez un addisonien traité. Bull Mém Soc. Hôp. Paris 1958, 74: 935-939.

9. Mollaret, P., Goulon, M. \& Tournilhac, M. Contribution à l'étude des paralysies avec hyperkaliémie I. Rôle de l'insuffisance cortic-surrénalienne. Rev Neurol (Paris) 1958, 98: $341-357$.

10. Pollen, R.H. \& Williams, R.H. Hyperkalemic neuromyopathy in Addison's disease. $N$ Engl $J$ Med 1960, 263: 273-278.

11. Faw, M.L. \& Ewer, R.W. Intermittent paralysis and chronic adrenal insufficiency. Ann Intern Med 1962, 57: $461-463$.

12. Posner, J.B. \& Jacobs, D.R. Isolated analdosteronism. A clinical entity with manifestations of persistent hyperkalaemia, periodic paralysis, salt-losing tendency and acidosis. Metabolism 1964, 13: 513-521.
13. Bell, H., Hayes, W.L. \& Vosburgh, J. Hyperkalemic paralysis due to adrenal insufficiency. Arch Int Med 1965, 115: 418-420.

14. Humair, L. \& Pfenninger, A. Paralysie hyperkaliémique chez une addisonienne traitée. Rev Med Suisse Rom 1965, 85: 619-625.

15. Daughaday, W.H. \& Rendleman, D. Severe symp- tomatic hyperkalemia in an adrenalectomized woman due to enhanced mineralocorticoid requirement. Ann Intern Med 1967, 66: 1197-1203.

16. Van Dellen, R.G. \& Purnell, D.C. Hyperkalemic paralysis in Addison's disease. Mayo Clin Proc 1969, 44: 904-914.

17. Waron, M., Alkan, W.J. \& Mera, A. Hyperkalemic quadriplegia in Addison's disease without hyperpigmentation. Israel J Med Sci 1970, 6: 650-654.

18. Schwieger, A.C. Hyperkalaemic periodic paralysis associated with Addison's disease. Proc Aust Assoc Neurol 1973, 9: 63-66.

19. De Fronzo, R.A. Hyperkalemia and hyporeninemic hypoaldosteronism. Kidney Int 1980, 17: 118-134. 